\title{
Two-choice conditional discrimination performance of pigeons as a function of reward expectancy, prechoice delay, and domesticity
}

\author{
DAVID L. BRODIGAN \\ Carleton College, Northfield, Minnesota 55057 \\ and \\ GAIL B. PETERSON \\ University of Minnesota, Minneapolis, Minnesota 55455
}

\begin{abstract}
In a discrete-trial two-choice conditional discrimination task, pigeons which received food for a correct choice following the presentation of one cue and water for a correct choice following another cue performed better than pigeons which received food and water equally often in both cases when delays of several seconds intervened between the conditional cue and choice stimuli presentations. These results suggest that feedback properties of reinforcer-specific expectancies can be important in conditional discrimination learning in pigeons. An additional finding was that wild-caught pigeons regularly exhibited a higher percentage of correct choices than domestic subjects.
\end{abstract}

According to one version of two-process learning theory, a stimulus which is regularly paired with some reinforcing event comes to evoke an expectancy of that reinforcing event. This expectancy is believed to have its own characteristic stimulus properties which are capable of entering into associative connections with instrumental responses in the same manner that external environmental stimuli do.

Direct evidence that expectancies based on different reinforcing agents have specific stimulus consequences to which instrumental responses can be conditioned has been provided by Trapold (1970). In that study, the use of a qualitatively different reinforcer for each of the two "correct" responses in a two-choice discrimination task produced faster discrimination learning in rats than did the use of either reinforcer alone for both responses.

The results of Trapold's study strongly support the idea that qualitative characteristics of reinforcers produce expectancies which have discriminably different stimulus properties, and later research has identified additional dimensional characteristics of reinforcers of importance in expectancy learning. In a classical-toinstrumental transfer of control study employing a two-stimulus, two-response discrimination task with rats, Gross (1971) found that magnitude of food reinforcement was an important property of reinforcers in expectancy learning. In another study, Carlson and Wielkiewicz (1972) showed that delay of reinforcement can have similar effects. The list of dimensional characteristics along which expectancies may be learned has been expanded by Overmier, Bull, and Trapold (1971)

This research was supported by National Institute of Mental Health Grant MH 18053 to Milton A. Trapold. Reprint requests should be sent to David L. Brodigan, Carleton College, Northfield, Minnesota 55057 . to include locus of electric shock application in dogs. The present study represents an attempt to expand the list of species of animals and of paradigms which show effects of differential reinforcement of the kind referred to above. Specifically, the purpose was to determine if reinforcer-specific expectancies exist in pigeons. If pigeons develop reinforcer-specific expectancies which have distinctive feedback properties, then in a two-choice conditional discrimination problem, pigeons which receive qualitatively different reinforcers for the different correct choices should perform better than pigeons which receive those reinforcers on an irregularly intermixed, equiprobable basis for both correct choices.

In the present experiment, pigeons were maintained under simultaneous food and water deprivation. On half of the trials food was the available reinforcer, while on the remaining trials water was available. Since both deprivation conditions were imposed continually, discriminative performance could not be based on driverelated internal stimuli alone. Therefore, although employing two different deprivation conditions, this study, based on the notion that different reinforcers have specific feedback stimuli, is to be distinguished from studies which have demonstrated that drive states can be discriminated (e.g., Amsel, 1949; Hull, 1933; Kendler, 1946; Leeper, 1935) and from studies showing that animals can discriminate drive intensities (e.g., Bloomberg \& Webb, 1949; Jenkins \& Hanratty, 1949).

An additional purpose of the research was to assess the possibility that different experiential and/or hereditary factors contribute to the learning or operation of reinforcer-specific expectancies. Accordingly, the performance of domestic white king and wild pigeons was compared in the two treatment conditions of the study. 


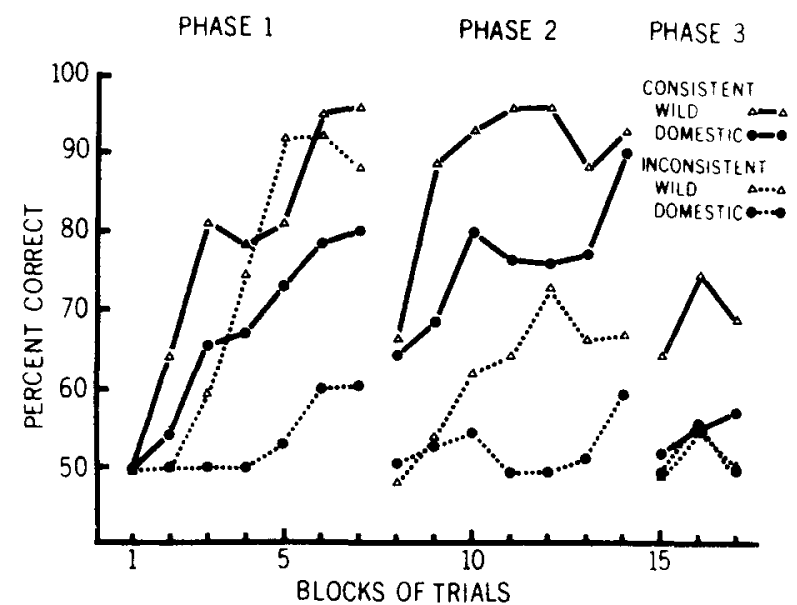

Figure 1. The performance of wild and domestic pigeons over successive 300 -trial blocks (100 trials/session) of a conditional two-choice discrimination task as a function of the consistency of the type of reward for correct responses and the delay between cue and choice. In Phase 1 the delay was 0 sec; it was $3 \mathrm{sec}$ in Phase 2 and $15 \mathrm{sec}$ in Phase 3.

\section{METHOD}

\section{Subjects}

The subjects were four white king pigeons obtained from Ronson Farms of Columbus, Ohio, and four wild pigeons captured locally by the experimenters.

\section{Apparatus \\ The apparatus included a Grason-Stadler Model 1122 pigeon operant conditioning chamber and conventional electromechan- ical event programming and data recording equipment. The intelligence panel of the operant conditioning chamber was equipped with three translucent response keys, a solenoid operated food hopper, a water delivery mechanism, and a continuously illuminated, unshielded houselight.}

\section{Procedure}

Prior to the beginning of the experiment, the subjects were assigned randomly to two groups with the constraint that each group contain two domestic white king and two wild pigeons. Each pigeon was reduced to $80 \%$ of its free-feeding weight and maintained at that weight throughout the experiment by a single feeding of Purina Pigeon Chow following each daily session.

Preliminary training included an initial session of apparatus habituation and 26 subsequent sessions of nondifferential classical conditioning. Each daily conditioning session contained 50 discrete $3-\mathrm{sec}$ presentations of Canadian field peas and 50 discrete presentations of approximately $.2 \mathrm{ml}$ of water. Each of these US events was preceded by a 3-sec presentation of white light (CS) on the center key. Intertrial intervals averaged $30 \mathrm{sec}$. Each pigeon was observed daily during this phase and throughout the experiment to determine whether it pecked the key, ate food, and drank water on a regular basis. Water rations were given after each session and were adjusted as necessary to insure that the subject would take both food and water during the next day's session. These rations varied between 5 and $20 \mathrm{ml}$ for every bird and were adjusted on a day-to-day basis.

The experiment proper involved a discrete trial procedure in which the correct choice between a horizontal line pattern stimulus and a vertical line pattern stimulus, projected simultaneously on the side keys, was conditional upon the color (red or green) of the preceding stimulus projected on the center key. ${ }^{1}$ Each trial began with the presentation of either green or red light on the center key Onset of the choice stmmul and offset of the center key stimulus were contingent upon five pecks to the center key stimulus with the esception that on Day 1 only one response was requared. Trials terminated following a single peck to elther choice stimulus. Correct chorces produced a reinforcement, incorrect chorces darkened he keys and advanced the pigeon to the intertrial interval.

For one group of pigeons, the consistent group, the relationship between the conditional choice problem stimuli and the type of reinforcer for correct choices was consistent. That is, a correct choice following one conditional stimulus was consistently rewarded with food, while a correct choice following the other conditional stimulus was always rewarded with water. Pigeons in the second group, the inconsistent group, received food or water on an irregularly intermixed, equiprobable basis for correct choices following either conditional stimulus.

Each session consisted of 100 trials with an intertrial interval of 5 sec. Relations between conditional stimuli and the "correct" choice stimuli and the relations between stimuli and reinforcer types were counterbalanced within groups.

The experiment was conducted in three successive phases which differed only in the length of the delay interval between the offset of the conditional stimulus and the onset of the choice stimuli. The delays were 0,3 , and $15 \mathrm{sec}$ for Phases 1,2 , and 3 , respectively. Phases 1 and 2 consisted of 21 sessions each, while Phase 3 contained 9 sessions.

\section{RESULTS}

Figure 1 presents the results in terms of percentages of correct responses for blocks of 300 trials (100/session). Within the consistent and inconsistent groups, the results are plotted separately for the wild and domestic pigeons.

In Phase 1, when the zero delay condition was in effect, the performance of pigeons in the consistent group was generally superior to that of pigeons in the inconsistent group. However, this difference was not statistically significant $(F=2.5, \mathrm{df}=1 / 4, \mathrm{p}<.25)$, according to a Group by Strain by Block analysis of variance.

In Phase 2, when the delay between the conditional and choice stimuli was $3 \mathrm{sec}$, pigeons in the consistent group again performed better than pigeons in the inconsistent group. In addition, within groups the wild pigeons were clearly superior to the domestic pigeons. Analysis of variance yielded significance for both of these results $(F=99.2, \mathrm{df}=1 / 4, p<.001 ; F=19.2$, $\mathrm{df}=1 / 4, \mathrm{p}<.02 .5)$.

Finally, in Phase 3, the same pattern of differences persisted when the delay was increased to $15 \mathrm{sec}$. The consistent group performed better than the inconsistent group $(F=120.1, d f=1 / 4, p<.0005)$ and the performance of the wild pigeons was superior to that of the domestic birds $(F=64.6, \mathrm{df}=1 / 4, \mathrm{p}<.0005)$.

An additional observation made during the course of this experiment was that the response topographies shown by subjects in the consistent group depended upon the particular reinforcer operationally associated with the conditional stimuli. That is, pigeons showed one response topography to the stimuli associated with food and another response topography to the stimuli 
paired with water. No such differential response topography was seen in birds of the inconsistent group.

\section{DISCUSSION}

The differences observed between pigeons in the consistent and inconsistent groups, especially in Phases 2 and 3 , indicate that pigeons develop reinforcer-specific expectancies and that those expectancies have distinct feedback properties to which different responses may be conditioned. Although the difference between these groups during the Phase 1 zero-delay condition cannot be viewed as a strong one, the differences seen in the delay conditions of Phases 2 and 3 can be attributed to the operation of reinforcer-specific expectancies.

The different response topographies exhibited to the food-associated and water-associated conditional stimuli by the subjects of the consistent group correspond to the observations obtained using autoshaping procedures with pigeons reported by Jenkins and Moore (1973) and Moore (1973). Pigeons emitted sharp, open-beak pecks in response to food-associated stimuli and slower, more sustained key contacts, often accompanied by swallowing movements, in response to water-associated stimuli. This set of observations leads to the general conclusion that the form of the pigeon's key-directed response is determined by the nature of the reinforcer.

It is possible that these differential response topographies mediated correct responses during delays between the conditional stimulus and the choice stimuli. If the cue associated with water elicited drinking-like responses, these responses or components of them may have continued to occur throughout the delay period and served as cues for the correct choice response. A similar mediation process could have operated to support correct performance on food-rewarded trials. That mediational responses may occur in delayed conditional discrimination problems in pigeons has been suggested previously by Blough (1959) and studied explicitly by Eckerman (1970). In Blough's experiment only a single type of reinforcer (food) was employed, and, therefore, the development of differential, reinforcer-specific mediational responses was precluded. However, Blough observed that the pigeons that performed well under delay conditions exhibited differential, idiosyncratic, stereotyped behaviors which could have served a mediational function. Eckerman (1970) also employed only one reinforcer type but required his pigeons to make cue-specific observing responses and found conditional discrimination performance to improve as a direct function of the difference between the responses to the cues. The use of qualitatively different reinforcers such as were employed in the present experiment may serve to facilitate or insure the development of distinct mediational responses in conditional discrimination problems with pigeons. That is, the operation of instrumental mediation during the prechoice delay period may be facilitated by the existence of different response topographies to the conditional cues already determined by the specific reinforceing agents. This analysis, which places emphasis upon the response-reinforcer relation, is consistent with the theories and data of a number of workers (e.g., Cumming, Berryman, \& Cohen, 1965; Lawrence, 1963; Schoenfeld \& Cumming, 1963).

An alternative mediational analysis (e.g., Osgood, 1953), and one more closely related to the concept of expectancy learning, emphasizes the stimulus-reinforcer rather than the response-reinforcer relation as the major factor in this situation. An experimental manipulation which might provide data indicating the relative validity of these viewpoints involves exchanging the reinforcers associated with each conditional cue for subjects which have received the consistent training treatment and have attained asymptotic performance under delay conditions. According to the instrumental response-mediation hypothesis, this change should result in little to no decrement in correct choice behavior, since effective mediating responses would already be established and continue to be reinforced, albeit with different reinforcers. The other hypothesis predicts that a substantial performance decrement would result since the stimulusreinforcer relationships were drastically altered. A gradual recovery in performance would occur as the new stimulus-reinforcer combinations were learned.

These analyses are based on an overt response interpretation of the mediational mechanism. It should be noted, however, that our observation of US-specific response topographies does not necessarily force the conclusion that the mediational mechanism is peripheral, since centrally located expectancies could underlie the peripheral effects.

Finally, the finding that the performance of wild pigeons was superior to that of domestic pigeons raises the question of whether that superiority may be attributed to genetic or experimental factors. A meaningful answer to this question would require rearing members of each strain under identical conditions. However, regardless of the relative contributions of genetic and environmental factors to the differences observed, the fact that wild and domestic birds differed significantly suggests that the extent to which the performance of domestic pigeons on various experimental tasks reflects the behavioral capacities of the species in general must be evaluated with caution.

\section{REFERENCES}

Amsel, A. Selective association and the anticipatory goal response as explanatory concepts in learning. Joumal of response as explanatory concepts in learni
Experimental Psychology, 1949, 39, 785-799.

Bloomberg, R., \& Webb, W. B. Various degrees within a single drive as cues for spatial response learning in the white rat. Journal of Experimental Psychology, 1949, 39, 628-636.

Blough, D. S. Delayed matching in the pigeon. Journal of the Experimental Analysis of Behavior, 1959, 2, 151-160. 
Carlson, J. G., \& Wielkıewicz, R. M. Delay of reinforcement in instrumental discrimination learning of rats. Journal of Comparative and Physiological Psychology, 1972, 81 . 365-370.

Carter, D. E., \& Eckerman, D. A. Symboilc matchıng by pigeons Rate of learning complex discriminations predicted from simple discriminations. Science, $1975,187,662-664$.

Cumming, W. W. Berryman, R., \& Cohen, L. R. Acquisition and transfer of zero-delay matching. Psychological Reports. $1965,17,435-445$.

Eckerman, $\dot{D}$. A. Generalization and response mediation of a conditional discrimination. Journal of the Experimental Analysis of Behavior, 1970, 13,301-316.

Gross, D. M. Learned expectancies of rats based on differential magnitudes of reinforcement. Unpublished PhD thesis, University of Minnesota. 1971.

Hull, C. L. Differential habituation to internal stimuli in the albino rat. Journal of Comparative Psychology, 1933, 16, 255-273

Jenkins, H. M.. \& Moore, B. R. The form of the auto-shaped response with food or water reinforcers. Journal of the Experimental Analysis of Behavior, 1973, 20, 163-181.

Jenkins, J J.. \& Hanratty, J. A. Drive intensity discrimination in the white rat. Journal of Comparative and Physiological Psychology, 1949, 42, 228-232.

Kendler, $H$. $H$. The influence of simultaneous hunger and thirst drives upon the learning of two opposed spatial responses of the white rat. Journal of Experimental Psychology. ses of the white rat.
$1946,36,212-220$.

Lawrence, D. H. The nature of a stimulus: Some relationships between learning and perception. In S. Koch (Ed.), Psychology 4 study of a science. Vol. 5. New York: McGraw-Hill, 1963 .
Leeper. $R$. The role of motivation in learung. A study of the phenomenon of differential motivational control of the utulization of habits. Journal of Genetic Psychologv. 1935. $46,3-40$

Moore, $B . R$. The role of directed Pavlovan reactions in simple instrumental learning in the pigeon. In $R$. A Hinde and J.S. Hinde (Eds.). C'onstraints on learnins. London Academic Press, 1973

Osgood, C. E Metinod and theory in experimental psychology New York Oxford University Press, 1953

Overmier. J B. Bull J A III, \& Trapold, M. A. Discriminative cue properties of different fears and their role in response selection in dogs. Journal of Comparative and Physiological Psychology, 1971, 76, 478-482.

Schoenfeld, W. N., \& Cumming. W. W. Behavior and perception In S. Koch (Ed.), Psychology A study of a science. Vol. 5. New York: McGraw-Hill, 1963.

Trapold. M. A. Are expectancies based upon different positive reinforcing events discrimunably different? Learning and Motivation, 1970, 1.129-140.

\section{NOTE}

1. The procedure employed in this experiment is formally identical to that labeled "symbolic matching" by Carter and Eckerman (1975).

(Received for publication May 16, 1975, revision accepted September $15,1975$. 